\title{
Combined Applications of Repurposed Drugs and Their Detrimental Effects on Glioblastoma Cells
}

\author{
ALEKSANDRA SACHKOVA, SWETLANA SPERLING, DOROTHEE MIELKE, \\ BAWARJAN SCHATLO, VEIT ROHDE and MILENA NINKOVIC \\ The Translational Neurooncology Research Group, Department of Neurosurgery, \\ University Medical Center Göttingen, Göttingen, Germany
}

\begin{abstract}
Background/Aim: Glioblastoma multiforme (GBM) is a malignant primary brain tumor with high rates of recurrence. This study aimed to investigate the effect of repurposed drug combinations on GBM. Materials and Methods: Viability of U87 MG and 11ST patient-derived GMB cell lines, after valproic acid, tranylcypromine or riluzole alone, in different combinations, as well as combined with standard temozolomide chemotherapy was examined using the MTT assay. Proliferation, mRNA level of tissue factor pathway inhibitor 2 (TFPI2), and cell invasion were evaluated using anti-Ki-67 antibody staining, reverse transcriptase-polymerase chain reaction and $x C E L L i g e n c e$ system. Results: The strongest effect on cell viability was achieved by the combination of riluzole with valproic acid (U87MG: 27.2\%, 11ST: 25.99\%). Tranylcypromine significantly enhanced the effect of temozolomide when used in combination, as did valproic acid. The normally high proliferation of GBM significantly declined under treatment with valproic acid with tranylcypromine $(p=0.01)$. Finally, we observed reduction of invasion comparing single tranylcypromine to its combination with valproic acid or riluzole. Conclusion: These results support the idea that combinations of drugs could increase the treatment efficiency of GBM.
\end{abstract}

Despite intensive research and improvement in medical care, glioblastoma multiforme (GBM) remains one of the most aggressive types of solid tumors, with a 2-year survival rate of less than $30 \%$ (1). Surgical resection followed by concomitant radiochemotherapy is the standard-of-care

Correspondence to: Milena Ninkovic, The Translational Neurooncology Research Group, Department of Neurosurgery, University Medical Center Göttingen, Robert-Koch-Strasse 40, 37075 Göttingen, Germany. Tel: +49 5513922966, Fax: +49 551398794, e-mail: milena.ninkovic@med.uni-goettingen.de

Key Words: Glioblastoma cells, combined treatment, standard of care treatment, proliferation, cell death. treatment for newly-diagnosed GBM, but ultimately fails to prevent disease progression. One of the reasons for the poor therapeutic effect is the great molecular heterogeneity of these tumors. Combination treatment directed against different tumor-driving molecular pathways might minimize drug resistance by making cancer cells incapable of adapting to simultaneous toxic effects (2).

Epigenetic mechanisms play an important role in GBM pathogenesis (3). Histone-modifying enzymes influence gene expression by regulating the condensation of chromatin and the access of nuclear proteins to their target genes (4). The ability of histone deacetylase (HDAC) and histone demethylase inhibitors, members of the class of epigeneticmodifying drugs under active development, to induce apoptosis, differentiation and chemo-sensitization of cancer cells has suggested their use in the treatment of numerous malignancies (5).

Treatment with the classical antiepileptic drug valproic acid (VPA), a non-selective inhibitor of HDAC class I and II (6), was shown to be associated with improved overall survival of patients with GBM (7). The phase II trial of VPA with standard radio-and chemotherapy led to a median overall survival of 29.6 months and progression-free survival of 10.5 months (8), exceeding survival obtained by standard regimens (1). There are several ongoing prospective trials evaluating the use of VPA in combination with other agents for treatment of adult and pediatric high-grade gliomas [reviewed in (3)]. The classical antidepressant drug, tranylcypromine (TCA), an inhibitor of monoamine oxidase $\mathrm{A}$, is known to target lysine-specific histone demethylases LSD1 and -2 (9). The activity of various transcription factors and nuclear receptors is regulated by LSD1 (10), which is also able to directly target important cellular proteins such as P53 (11). Lysine-specific histone demethylase 1 is involved in neuronal differentiation processes and promotes the stemness phenotype (12). It is also part of the complex acting as a key effector of the regulatory program of GBM stem-like cells, and its knockdown causes GBM stem-like cells to lose their capacity to initiate tumors in vivo (13). 

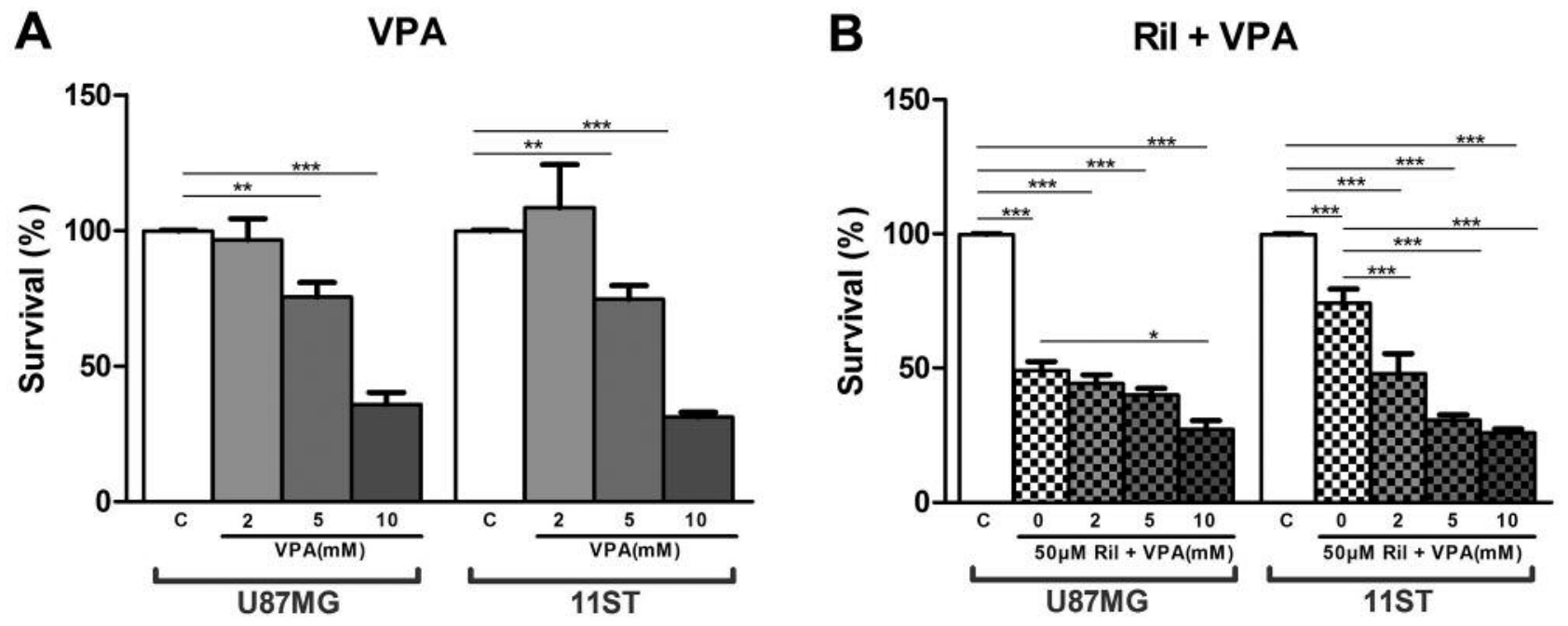

Ril
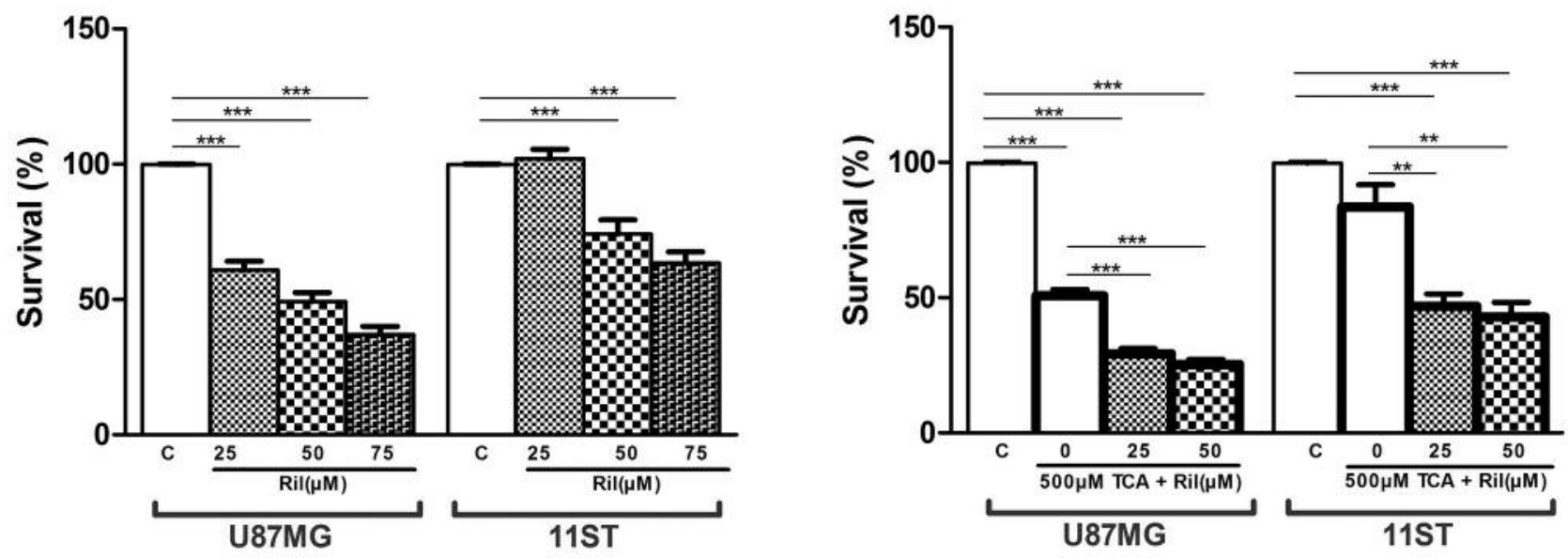

TCA
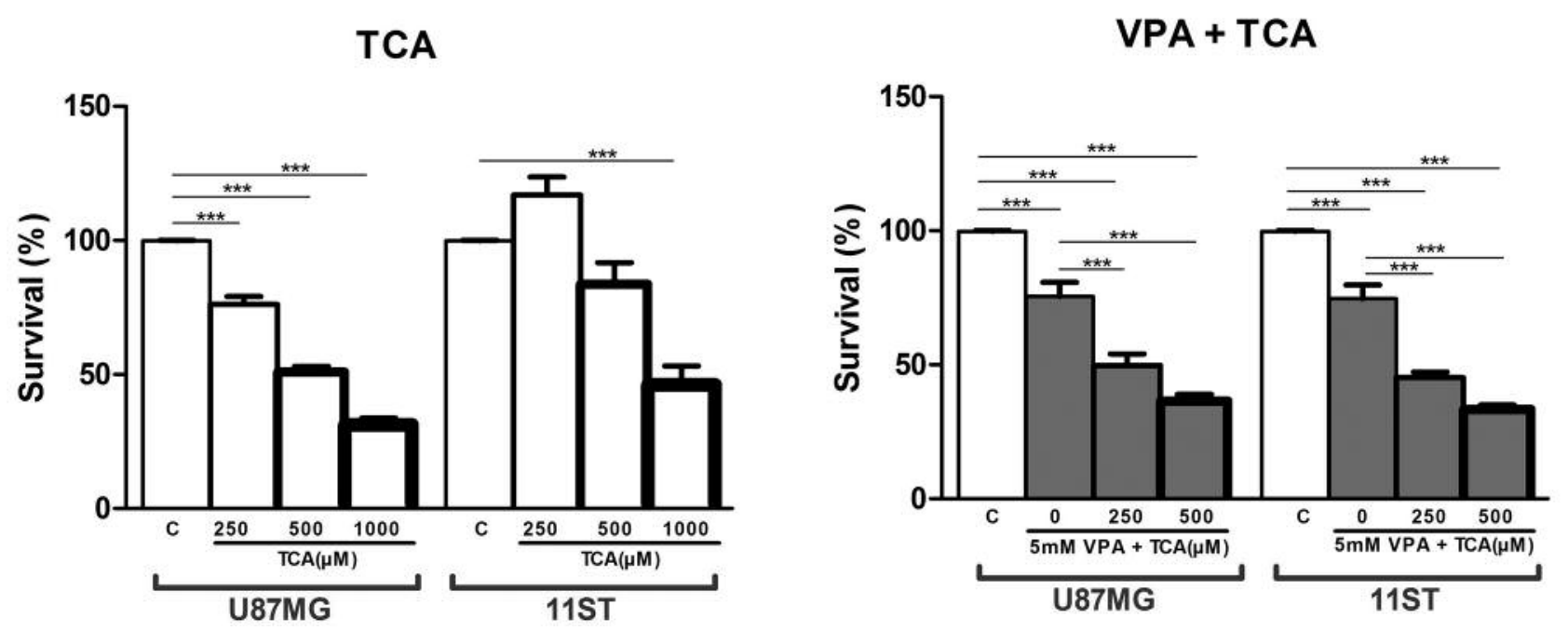

Figure 1. Continued 

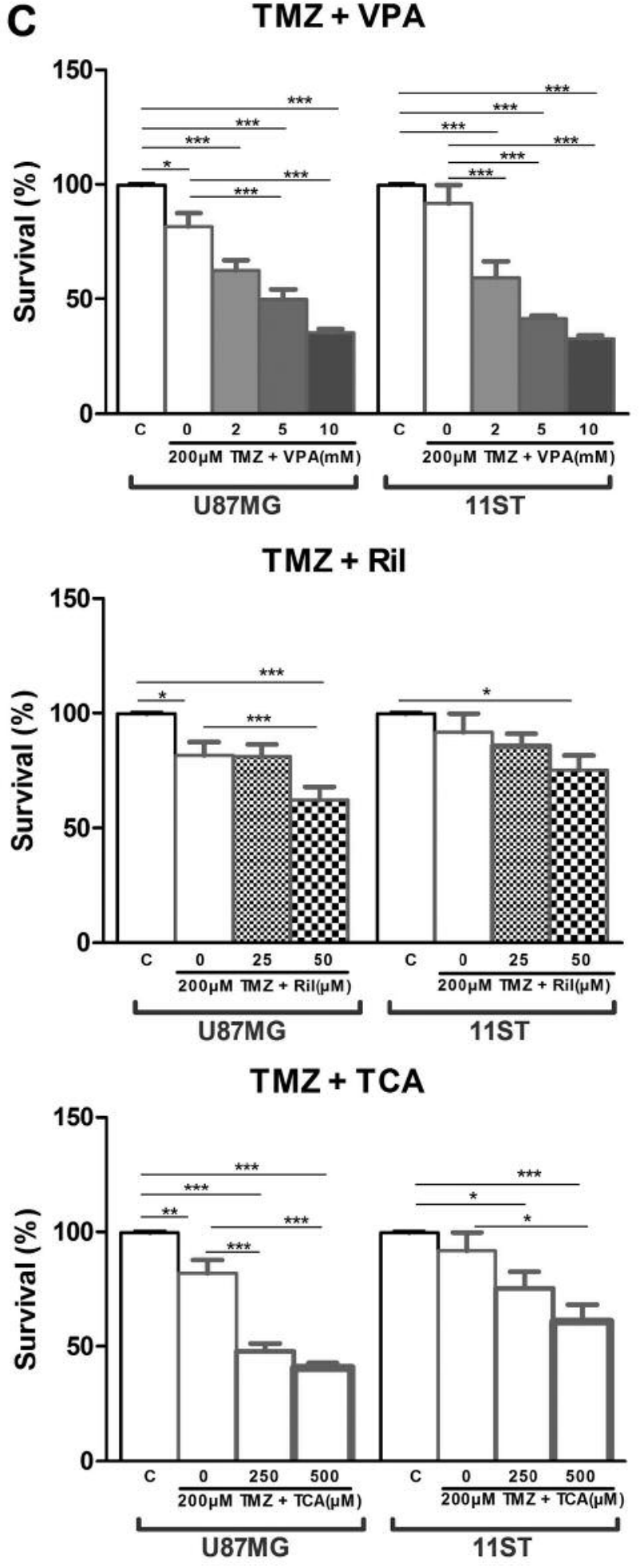

Figure 1. MTT assays for U87MG and 11ST viability after treatment with valproic acid (VPA), tranylcypromine (TCA), and riluzole (Ril) alone (A), or in combination $(B)$, and combined with temozolomide $(T M Z)(C)$. Data are the mean $\pm S E M$. Results of at least three independent experiments are presented. C: Control. Statistical analysis was performed using one-way ANOVA. Significantly different at: ${ }^{*} p<0.05,{ }^{*} p<0.01$, and ${ }^{* * *} p<0.001$.
TCA has been shown to have in vivo and in vitro effects against several cancer types and is being tested in clinical trials (14).

One of the factors contributing to the aggressive proliferative behavior of GBM is abnormal glutamate release. Excessive glutamate is toxic to the normal cells surrounding a tumor. Riluzole, the only United States Food and Drug Administration-approved medication for the treatment of amyotrophic lateral sclerosis, can reduce both the release of glutamate and glutamate-induced toxicity in brain tissue (15). Yelskaya et al. showed that blocking glutamate release in the GBM cell line U87MG using riluzole inhibited cell proliferation (16). Recently, the effect of riluzole on the down-regulation of glucose transporter 3 (17), known to be important for the tumorigenic potential of radio-and chemoresistant GBM stem-like cells (18), was reported. Riluzole has been shown to be effective in various cancer models (19-21) and has been explored in clinical trials for melanoma therapy (22).

In this project, we tested different combinations of VPA, TCA and riluzole in order to target different pathways involved in GBM pathogenesis. We examined the effects of these drugs, alone and in combination, on cell viability, proliferation and invasion. Their role in sensitization for standard chemotherapy with temozolomide was also studied.

\section{Materials and Methods}

Materials and cell culture. Cell culture media, fetal bovine sera and other supplements were purchased from Gibco Life Technologies (Carlsbad, CA, USA). VPA was purchased from Sigma-Aldrich (St. Louis, MO, USA), riluzole from TOCRIS (Bristol, UK), temozolomide from MSD Sharp \& Dohme GmbH (Haar, Germany) and TCA from Abcam (Cambridge, UK). VPA, TCA and riluzole were dissolved in double-distilled water. Temozolomide was dissolved in dimethyl sulfoxide (Sigma-Aldrich). U87MG GBM cells were gift from Julia Bode (Molecular Mechanisms of Tumor Invasion, Schaller Research Group at the University of Heidelberg and the DKFZ). The 11ST cell line was derived from a patient's primary GBM sample from the Neurosurgical Department, University Medical Center Göttingen, Germany, according to the following protocol: fresh tumor tissue was rinsed in cold phosphatebuffer solution $(1 \times$ PBS $)$, minced by scalpel and passed through a $30 \mu \mathrm{m}$ cell strainer (Miltenyl Biotech, Bergisch Gladbach, Germany) in $500 \mu \mathrm{l}$ of $1 \times$ PBS. The single-cell culture was then added to $5 \mathrm{ml}$ minimum essential medium (ThermoFisher Scientific, Waltham, MA, USA) culture medium supplemented with $10 \%$ fetal bovine serum (FCS), $2 \mathrm{mM}$ L-glutamine and $1 \mathrm{mM}$ sodium pyruvate and transferred to a T25 cell culture flask until it reached $60-80 \%$ of confluence in the presence of penicillin/streptomycin (ThermoFisher Scientific).

Cell viability assay. Cell viability assays were performed using 3-(4, 5-dimethylthiazol)-2, 5-diphenyltetrazolium bromide (MTT; Sigma-Aldrich, St. Louis, MO, USA). Cells were seeded into 96-well plates at a final density of $15 \times 10^{3}$ cells/well. Cells were allowed $24 \mathrm{~h}$ to attach and then treated with following concentrations 
of (i) single drugs: 2, 5, $10 \mathrm{mM}$ VPA; 250, 500, $1000 \mu \mathrm{M}$ TCA; 25, $50,75 \mu \mathrm{M}$ riluzole; (ii) combination of the drugs $50 \mu \mathrm{M}$ riluzole +2 , $5,10 \mathrm{mM}$ VPA; $500 \mu \mathrm{M} \mathrm{TCA}+25,50 \mu \mathrm{M}$ riluzole; $5 \mathrm{mM} \mathrm{VPA}+$ 250, $500 \mu \mathrm{M}$ TCA; and (iii) $200 \mu \mathrm{M}$ temozolomide with: 2, 5, 10 $\mathrm{mM}$ VPA; or $25,50 \mu \mathrm{M}$ riluzole; or $250,500 \mu \mathrm{M}$ TCA respectively. The drugs were added to each well in $10 \mu$ l of $10 \times$ concentrated drug solution diluted in $100 \mu$ of FCS-free medium. After $72 \mathrm{~h}$, MTT was added and the cell cultures were incubated for a further $4 \mathrm{~h}$ at $37^{\circ} \mathrm{C}$. Samples were measured with a spectrophotometer absorption reader (Bio-TEK, Winooski, VT, USA) via absorbance at $562 \mathrm{~nm}$.

Cell proliferation assay and immunocytochemistry. Cells were seeded in three replicates on 24-well plates containing poly-D-lysincoated glass coverslips at $120 \times 10^{3} /$ well. The cells were given $24 \mathrm{~h}$ to attach and then treated for the next $24 \mathrm{~h}$ with drug-containing media. After $24 \mathrm{~h}$, the cells were fixed with acetone for $20 \mathrm{~min}$ at $-20^{\circ} \mathrm{C}$. After fixation, the coverslips were blocked with $10 \%$ horse serum for $20 \mathrm{~min}$, incubated with primary antibody to Ki67 (1:50; DAKO, Santa Clara, CA, USA) overnight at $4^{\circ} \mathrm{C}$ and visualized with Alexa 488 Fluor donkey anti-mouse secondary antibody (1:500; Life Technologies, Waltham, MA, USA). Nuclei were counterstained with 4',6-diamidino-2-phenylindole (DAPI; SigmaAldrich). The coverslips were dried at room temperature and mounted with Aqua-Poly/Mount medium (Polysciences, Inc., Eppelheim, Germany). Slides were studied with a ZEISS Axiovert 200 Fluorescence Microscope (Zeiss, Oberkochen, Germany). Ki67-positive cells were counted at $20 \times$ resolution. Quantification was performed in Neurolucida software (MBF Bioscience, Williston, VT, USA). The percentage of proliferating cells based on the total number of Ki-67-positive cells divided by the total number of DAPI-positive cells was calculated. For each treatment, at least five random microscopic fields were quantified. Each treatment was repeated at least three times.

Cell invasion assay. The rate of cell invasion was monitored in realtime with the xCELLigence system (ACEA Biosciences Inc., San Diego, USA) CIM plates. For $16 \mathrm{~h}$ prior to the experiment, U87MG cells were serum starved. The upper chamber of the CIM plates was coated with $20 \mu \mathrm{l}$ of $800 \mu \mathrm{g} / \mathrm{ml}$ solution of Matrigel $^{\mathrm{TM}}$ (BD Biosciences, Heidelberg, Germany). A total of 50,000 cells were seeded in each well of the upper chamber in serum-free media including $5 \mathrm{mM}$ VPA, $500 \mu \mathrm{M}$ TCA, or $50 \mu \mathrm{M}$ riluzole and combinations of these. Culture medium including 5\% FCS and the compounds were added to each well of the lower chamber. The electrode impedance value of each well was automatically monitored by the xCELLigence system for $4 \mathrm{~h}$ and expressed as the Cell Index.

RNA purification, reverse transcription, and real-time polymerase chain reaction for the analysis of tissue factor pathway inhibitor 2 (TFPI2) gene expression. Total cellular RNA was isolated with the RNeasy kit (Qiagen, Hilden, Germany) and reverse-transcribed into cDNA using the SuperScript III first-strand synthesis kit (Life Technologies). cDNA (100 ng) was used for real-time PCR amplification. Real-time PCR was performed on a BioRAD CFX384 cycler using iTaq universal SYBR-Green Mastermix (Bio-rad, Hercules, CA, USA) and gene-specific primers as follows: hydroxymethylbilane synthase $(H M B S)$ : forward: 5' CGC ATC TGG AGT TCA GGA GTA 3', reverse: 5' CCA GGA TGA TGG CAC TGA
3'; hypoxanthine phosphoribosyltransferase 1 (HPRT1): forward: 5' TGA CCT TGA TTT ATT TTG CAT ACC 3', reverse: 5' CGA GCA AGA CGT TCA GTC CT 3'; TFPI2: forward: 5' GTC GAT TCT GCT GCT TTT CC 3', reverse: 5' CAG CTC TGC GTG TAC CTG TC 3'.

Statistical analysis. Statistical analysis was performed using oneway ANOVA with Bonferroni post-hoc test.

\section{Results}

Effect of single and combined treatments on cell viability. Here we examined the effects of VPA, TCA and riluzole individually and in different combinations on two GBM cell lines. The effects of single treatments with VPA, riluzole or TCA on U87MG and 11ST cells are shown in Figure 1A. VPA at concentrations of 5 and $10 \mathrm{mM}$ significantly reduced survival of both cell lines. All concentrations of riluzole significantly reduced the viability of U87MG cells, while only $50 \mu \mathrm{M}$ and $75 \mu \mathrm{M}$ led to a statistically significant effect on 11ST cell survival. All three concentrations of TCA used were efficient in reducing U87MG cells, while TCA only influenced the survival rate of $11 \mathrm{ST}$ cells at $1000 \mu \mathrm{M}$.

Next, we combined different concentrations of VPA, TCA and riluzole to determine their potential improved effect on cell death (Figure 1B). The most prominent reduction in viability was achieved by the combination of $50 \mu \mathrm{M}$ riluzole and $10 \mathrm{mM}$ VPA. U87MG cells were highly sensitive to combinations of riluzole and $500 \mu \mathrm{M}$ TCA.

We then evaluated the combination of VPA, TCA and riluzole with first-line treatment agent temozolomide (at $200 \mu \mathrm{M})$. Treatment with temozolomide alone had only a moderate effect on cell death (Figure 1C) but combination with VPA or TCA significantly reduced viability of both cell lines in comparison.

Inhibition of GBM cell proliferation and invasion by combined drug treatment. An important hallmark of cancer, hence also of GBM, is a high proliferative rate. We tested

Figure 2. Beneficial effects of combined treatment on proliferation and migration of U87MG cells. A: Proliferation assay. U87MG cells were treated with $5 \mathrm{mM}$ valproic acid (VPA), $500 \mu \mathrm{M}$ tranylcypromine (TCA), and $50 \mu \mathrm{M}$ riluzole (Ril) and combinations of these for $24 \mathrm{~h}$. Cells were stained with anti-Ki67 (green). Nuclei were counterstained with 4',6diamidino-2-phenylindole (DAPI) (blue, 10× magnification). B: The rate of invasion of cells was monitored with an $x$ CELLigence system $(0-$ 4 h). Bars depict mean \pm SEM from three independent experiments. $C$ : Real-time monitoring of cell invasion, representative image is shown. D: Real-time polymerase chain reaction results showed that all combined treatments prominently up-regulated the expression of tissue factor pathway inhibitor 2 (TFPI2) in U87MG glioblastoma cells. Statistical analysis was performed using one-way ANOVA. Significantly different at: $* p<0.05$, and $* * p<0.01$. 

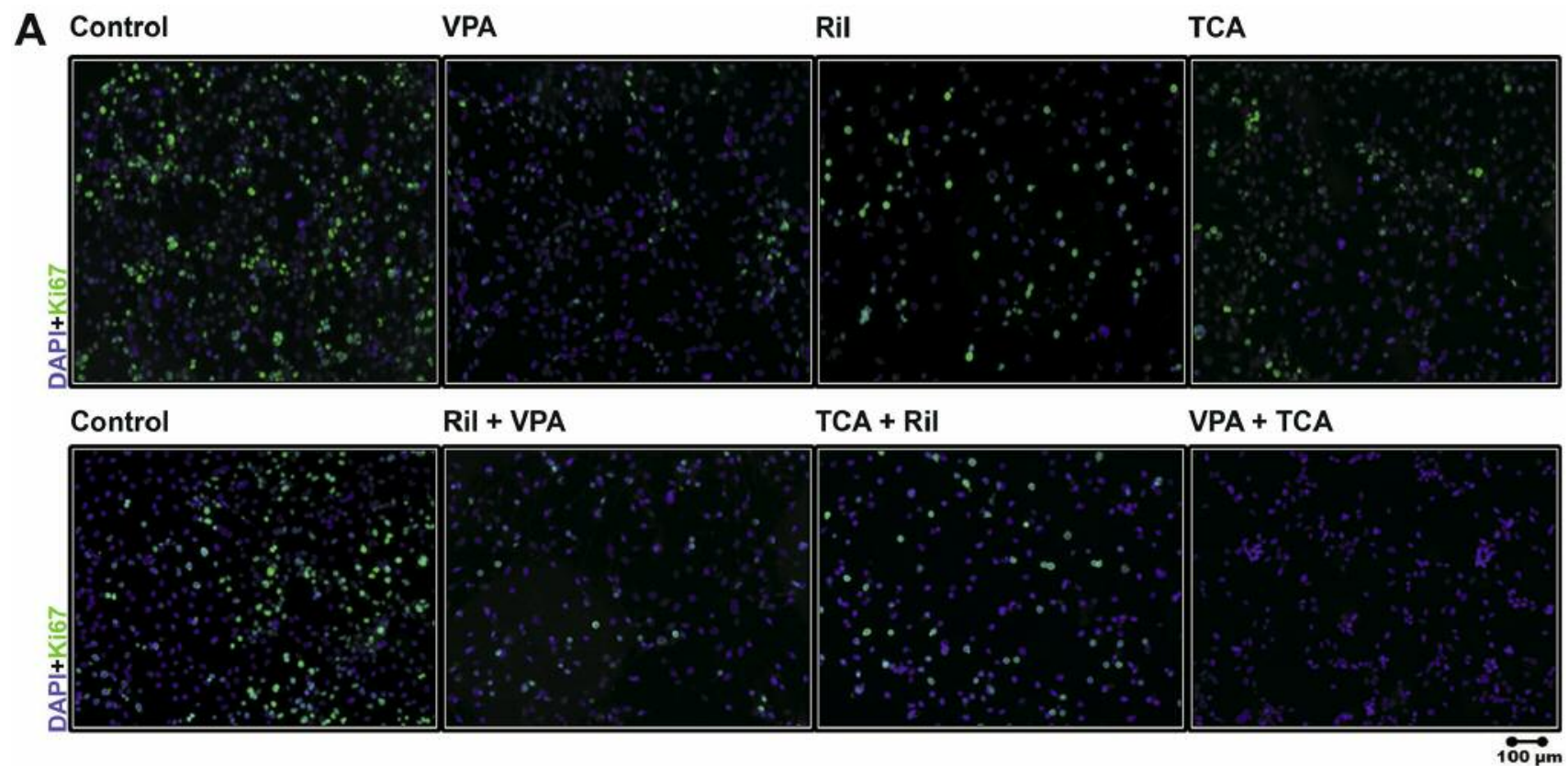

B

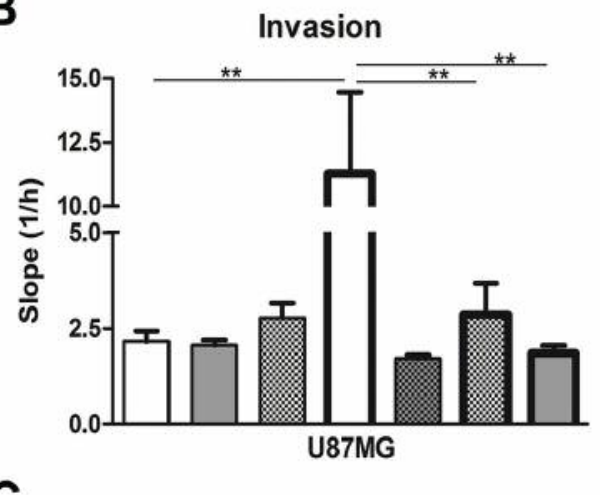

D

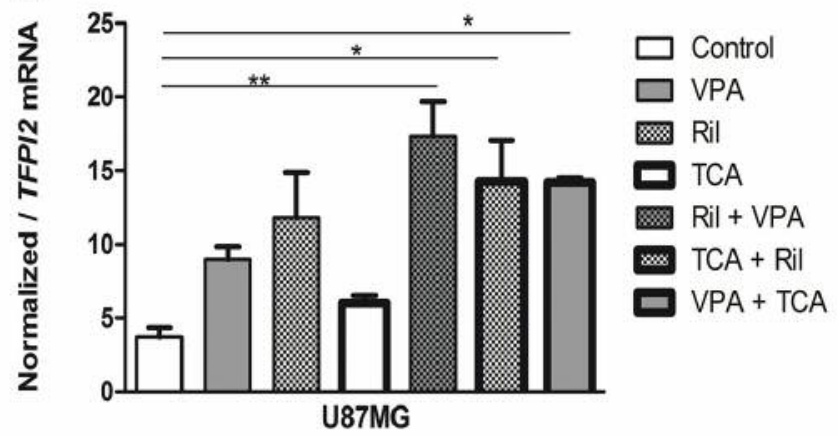

C

Invasion

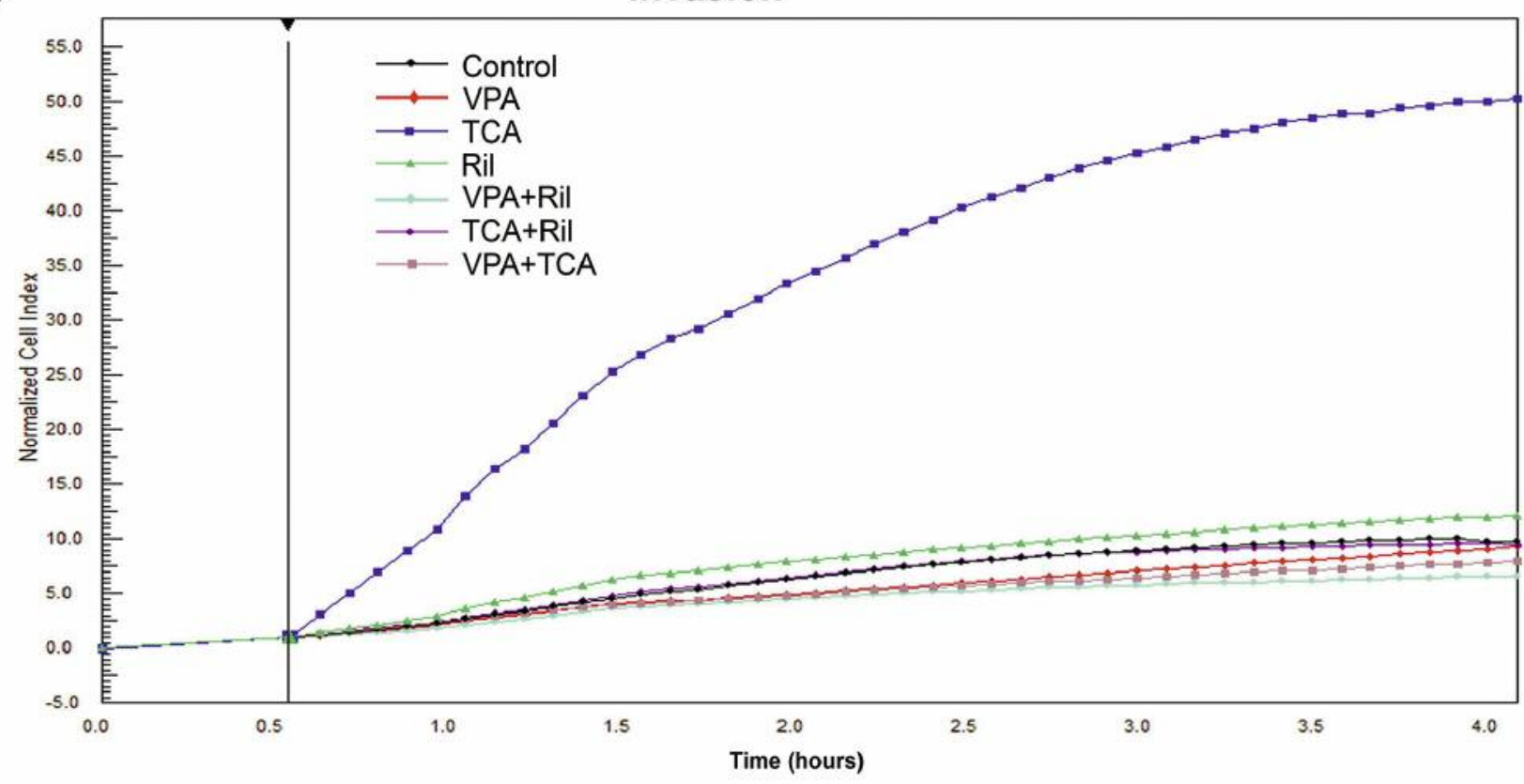


the influence of single and combinations of the drugs on the proliferation of the two cell lines. Compared to the control sample, treated samples had a reduced number of Ki-67positive cells (Figure 2A). The percentage of proliferating cells significantly declined under treatment with $5 \mathrm{mM}$ VPA $(p=0.038)$ and $500 \mu \mathrm{M}$ TCA $(p=0.014)$ and their combination $(p=0.01)$ (Figure $2 \mathrm{~A})$.

We also observed reduction of invasion (Figure 2B) comparing TCA treatment alone with the combination of VPA/TCA and TCA/riluzole. Even though not significant, slightly reduced invasion was detected comparing riluzole alone with its combination with VPA (Figure 2C). Additionally, we examined expression of TFPI2, a serine protease inhibitor which plays a role in remodeling of extracellular matrix. TFPI2 was found to be up-regulated using all three different combinations, confirming yet again the positive effect of combined treatment (Figure 2D).

\section{Discussion}

The great molecular heterogeneity of GBM is the key to its high radio- and chemoresistance. The number of experimental studies and clinical trials arguing for combined treatment is growing rapidly. This implies the utilization of various classes of drugs directed against the different oncogenic pathways that might be simultaneously activated in a heterogeneous population of tumor cells. Assuming that combination treatment might improve therapy, we evaluated repurposing of three drugs and their combination against two GBM cell lines.

Although with different response, all three tested drugs, VPA, riluzole and TCA, reduced viability of both cell lines. In our experiments, $11 \mathrm{ST}$ cells showed more resistance than U87MG towards TCA and riluzole treatment. This difference in response between U87MG and 11ST might be due to the difference in genetic background of these two cell lines. For example, it has been shown that TP53 status is important for the anticancer effect of TCA (23). Future experiments might help identify genetic signatures of tumors with special susceptibility to treatment with TCA with/without riluzole. Using different combinations of these three drugs, the most prominent viability reduction was achieved, for both cell lines, with the combination of riluzole and VPA. Additionally, the 11ST cells showed comparatively better effects under treatment with VPA/TCA (Figure 1B). Earlier studies showed the benefit of simultaneous treatment with HDAC and LSD1 inhibitors in different types of cancer $(23,24)$. HDAC class I and II and LSD1 cooperate in several transcriptional complexes, such as REST corepressor 1 (CoREST), which are known to act as transcriptional repressors and be involved in the development of cancer. Fiskus et al. demonstrated a synergistic effect of LSD1 inhibitor SP2509 with HDAC inhibitor panobinostat. They also showed that SP2509 prevented LSD1 assembly with CoREST (24). In another study, the combination of TCA with vorinostat, panobinostat and entinostat was able to reduce cancer cell viability, while the drug effect appeared to be dependent on TP53 expression (23). Furthermore, several studies have reported the additive and synergetic effect of VPA and temozolomide (25-27). The combination of temozolomide with the drugs used in this study might boost the effect of standard treatment. Indeed, the effect of single temozolomide treatment was significantly increased when temozolomide was combined with VPA or TCA in both cell cultures. The combination effect between standard chemotherapy and novel drugs might potentially allow a reduction in the therapeutic dosage of each individual medication (28).

Enhanced effect of combined VPA/TCA on inhibition of proliferation is in line with a synergistic effect on breast cancer cell proliferation which was achieved in another study by simultaneous inhibition of LSD1 and HDAC with pargyline and suberoylanilide hydroxamic acid (29).

The invasion of GBM cells into normal brain and the unlikeliness of complete surgical removal contribute to the lethality and recurrence of GBM (30). Beside the advantageous effect of TCA on reducing cell viability and proliferation, TCA had an unfavorable effect by increasing invasion. The combination of drugs (VPA/TCA or TCA/riluzole) reduced this effect, yet again showing benefits of combined treatment. The up-regulation of TFPI2 gene is another advantageous effect of these drug treatments. Direct influence of the TFPI2 on the reduction of the invasion was not examined in this study. TFPI2 is down-regulated in various tumors (31-33) including gliomas (34). In human gliomas, TFPI2 is down-regulated or lost during tumor progression (34). Its up-regulation in glioma cells was found to reduce invasion both in vitro and in in vivo (35).

In summary, combination treatment: (i) had a greater effect on cell survival than treatment with single drugs; (ii) was able to reduce tumor cell proliferation; (iii) increased the effect of conventional treatment with temozolomide; (iv) of TCA/riluzole and VPA/TCA reduced invasion compared to single TCA treatment.

Further evaluation of the use of drug combinations is inevitable, for example, examination of more cell lines with different genetic backgrounds, drug combinations applied in in vivo models and the determination of molecular susceptibility for treatment. But the potential of combination treatment in minimizing drug resistance by making cancer cells incapable of adapting to simultaneous toxic effects is supported by the results of this study.

\section{Acknowledgements}

The Authors would like to thank Julia Bode (Schaller Research Group at the University of Heidelberg and the DKFZ, Deutsches Krebsforschungszentrum (V077), Heidelberg, Germany) for the 
generous gift of the U87MG cell line, and Christoph Schmitz-Salue for the development of the 11ST cell line culture.

\section{Conflicts of Interest}

The Authors declare that they have no conflict of interest in regard to this study.

\section{Ethics Approval}

The study was approved by the ethical board of University Medical Center Goettingen. The 11ST cell line was derived from a patient primary GBM sample from the Neurosurgical Department, University Medical Center Goettingen, in agreement with the patient.

\section{References}

1 Stupp R, Hegi ME, Mason WP, van den Bent MJ, Taphoorn MJ, Janzer RC, Ludwin SK, Allgeier A, Fisher B, Belanger K, Hau P, Brandes AA, Gijtenbeek J, Marosi C, Vecht CJ, Mokhtari K, Wesseling P, Villa S, Eisenhauer E, Gorlia T, Weller M, Lacombe D, Cairncross JG, Mirimanoff RO; European Organisation for Research and Treatment of Cancer Brain Tumor and Radiation Oncology Groups; National Cancer Institute of Canada Clinical Trials Group: Effects of radiotherapy with concomitant and adjuvant temozolomide versus radiotherapy alone on survival in glioblastoma in a randomised phase III study: 5-year analysis of the EORTC-NCIC trial. Lancet Oncol 10(5): 459-466, 2009.

2 Zimmermann GR, Lehar $\mathrm{J}$ and Keith CT: Multi-target therapeutics: When the whole is greater than the sum of the parts. Drug Discov Today 12(1-2): 34-42, 2007.

3 Williams MJ, Singleton WG, Lowis SP, Malik K and Kurian KM: Therapeutic targeting of histone modifications in adult and pediatric high-grade glioma. Front Oncol 7: 45, 2017.

4 Maleszewska M and Kaminska B: Is glioblastoma an epigenetic malignancy? Cancers 5(3): 1120-1139, 2013.

5 Eckschlager T, Plch J, Stiborova M and Hrabeta J: Histone deacetylase inhibitors as anticancer drugs. Int J Mol Sci 18(7): E1414, 2017.

6 Lee P, Murphy B, Miller R, Menon V, Banik NL, Giglio P, Lindhorst SM, Varma AK, Vandergrift WA, 3rd, Patel SJ and Das A: Mechanisms and clinical significance of histone deacetylase inhibitors: Epigenetic glioblastoma therapy. Anticancer Res 35(2): 615-625, 2015.

7 Weller M, Gorlia T, Cairncross JG, van den Bent MJ, Mason W, Belanger K, Brandes AA, Bogdahn U, Macdonald DR, Forsyth P, Rossetti AO, Lacombe D, Mirimanoff RO, Vecht CJ and Stupp R: Prolonged survival with valproic acid use in the EORTC/NCIC temozolomide trial for glioblastoma. Neurology 77(12): 1156-1164, 2011.

8 Krauze AV, Myrehaug SD, Chang MG, Holdford DJ, Smith S, Shih J, Tofilon PJ, Fine HA and Camphausen K: A phase 2 study of concurrent radiation therapy, temozolomide, and the histone deacetylase inhibitor valproic acid for patients with glioblastoma. Int J Radiat Oncol Biol Phys 92(5): 986-992, 2015.

9 Zheng YC, Ma J, Wang Z, Li J, Jiang B, Zhou W, Shi X, Wang $X$, Zhao W and Liu HM: A systematic review of histone lysinespecific demethylase 1 and its inhibitors. Med Res Rev 35(5): 1032-1071, 2015.
10 Kozono D, Li J, Nitta M, Sampetrean O, Gonda D, Kushwaha DS, Merzon D, Ramakrishnan V, Zhu S, Zhu K, Matsui H, Harismendy O, Hua W, Mao Y, Kwon CH, Saya H, Nakano I, Pizzo DP, VandenBerg SR and Chen CC: Dynamic epigenetic regulation of glioblastoma tumorigenicity through LSD1 modulation of MYC expression. Proc Natl Acad Sci USA 112(30): E4055-4064, 2015.

11 Huang J, Sengupta R, Espejo AB, Lee MG, Dorsey JA, Richter M, Opravil S, Shiekhattar R, Bedford MT, Jenuwein T and Berger SL: P53 is regulated by the lysine demethylase LSD1. Nature 449(7158): 105-108, 2007.

12 Han X, Gui B, Xiong C, Zhao L, Liang J, Sun L, Yang X, Yu W, Si W, Yan R, Yi X, Zhang D, Li W, Li L, Yang J, Wang Y, Sun YE, Zhang D, Meng A and Shang Y: Destabilizing LSD1 by JADE-2 promotes neurogenesis: An antibraking system in neural development. Mol Cell 55(3): 482-494, 2014.

13 Suva ML, Rheinbay E, Gillespie SM, Patel AP, Wakimoto H, Rabkin SD, Riggi N, Chi AS, Cahill DP, Nahed BV, Curry WT, Martuza RL, Rivera MN, Rossetti N, Kasif S, Beik S, Kadri S, Tirosh I, Wortman I, Shalek AK, Rozenblatt-Rosen O, Regev A, Louis DN and Bernstein BE: Reconstructing and reprogramming the tumor-propagating potential of glioblastoma stem-like cells. Cell 157(3): 580-594, 2014

14 Maiques-Diaz A and Somervaille TC: LSD1: Biologic roles and therapeutic targeting. Epigenomics 8(8): 1103-1116, 2016.

15 Bellingham MC: A review of the neural mechanisms of action and clinical efficiency of riluzole in treating amyotrophic lateral sclerosis: What have we learned in the last decade? CNS Neurosci Ther 17(1): 4-31, 2011.

16 Yelskaya Z, Carrillo V, Dubisz E, Gulzar H, Morgan D and Mahajan SS: Synergistic inhibition of survival, proliferation, and migration of U87 cells with a combination of LY341495 and Iressa. PLoS One 8(5): e64588, 2013.

17 Sperling S, Aung T, Martin S, Rohde V and Ninkovic M: Riluzole: A potential therapeutic intervention in human brain tumor stem-like cells. Oncotarget 8(57): 96697-96709, 2017.

18 Flavahan WA, Wu Q, Hitomi M, Rahim N, Kim Y, Sloan AE, Weil RJ, Nakano I, Sarkaria JN, Stringer BW, Day BW, Li M, Lathia JD, Rich JN and Hjelmeland AB: Brain tumor initiating cells adapt to restricted nutrition through preferential glucose uptake. Nat Neurosci 16(10): 1373-1382, 2013.

19 Speyer CL, Smith JS, Banda M, DeVries JA, Mekani T and Gorski DH: Metabotropic glutamate receptor-1: A potential therapeutic target for the treatment of breast cancer. Breast Cancer Res Treat 132(2): 565-573, 2012.

20 Wen Y, Li J, Koo J, Shin SS, Lin Y, Jeong BS, Mehnert JM, Chen S, Cohen-Sola KA and Goydos JS: Activation of the glutamate receptor GRM1 enhances angiogenic signaling to drive melanoma progression. Cancer Res 74(9): 2499-2509, 2014.

21 Zhang C, Yuan XR, Li HY, Zhao ZJ, Liao YW, Wang XY, Su J, Sang SS and Liu Q: Anti-cancer effect of metabotropic glutamate receptor 1 inhibition in human glioma u87 cells: Involvement of PI3K/ AKT/mTOR pathway. Cell Physiol Biochem 35(2): 419-432, 2015.

22 Yip D, Le MN, Chan JL, Lee JH, Mehnert JA, Yudd A, Kempf J, Shih WJ, Chen S and Goydos JS: A phase 0 trial of riluzole in patients with resectable stage III and IV melanoma. Clin Cancer Res 15(11): 3896-3902, 2009.

23 Singh MM, Johnson B, Venkatarayan A, Flores ER, Zhang J, Su $\mathrm{X}$, Barton M, Lang F and Chandra J: Preclinical activity of combined HDAC and KDM1A inhibition in glioblastoma. Neuro Oncol 17(11): 1463-1473, 2015. 
24 Fiskus W, Sharma S, Shah B, Portier BP, Devaraj SG, Liu K, Iyer SP, Bearss D and Bhalla KN: Highly effective combination of LSD1 (KDM1A) antagonist and pan-histone deacetylase inhibitor against human AML cells. Leukemia 28(11): 21552164, 2014.

25 Hoja S, Schulze M, Rehli M, Proescholdt M, Herold-Mende C, Hau P and Riemenschneider MJ: Molecular dissection of the valproic acid effects on glioma cells. Oncotarget 7(39): 6298963002, 2016.

26 Hosein AN, Lim YC, Day B, Stringer B, Rose S, Head R, Cosgrove L, Sminia P, Fay M and Martin JH: The effect of valproic acid in combination with irradiation and temozolomide on primary human glioblastoma cells. J Neurooncol 122(2): 263-271, 2015.

27 Proske J, Walter L, Bumes E, Hutterer M, Vollmann-Zwerenz A, Eyupoglu IY, Savaskan NE, Seliger C, Hau P and Uhl M: Adaptive immune response to and survival effect of temozolomide-and valproic acid-induced autophagy in glioblastoma. Anticancer Res 36(3): 899-905, 2016.

28 Mokhtari RB, Kumar S, Islam SS, Yazdanpanah M, Adeli K, Cutz $\mathrm{E}$ and Yeger H: Combination of carbonic anhydrase inhibitor, acetazolamide, and sulforaphane, reduces the viability and growth of bronchial carcinoid cell lines. BMC Cancer 13: 378, 2013.

29 Huang Y, Vasilatos SN, Boric L, Shaw PG and Davidson NE: Inhibitors of histone demethylation and histone deacetylation cooperate in regulating gene expression and inhibiting growth in human breast cancer cells. Breast Cancer Res Treat 131(3): $777-$ $789,2012$.

30 Kegelman TP, Wu B, Das SK, Talukdar S, Beckta JM, Hu B, Emdad L, Valerie K, Sarkar D, Furnari FB, Cavenee WK, Wei J, Purves A, De SK, Pellecchia M and Fisher PB: Inhibition of radiation-induced glioblastoma invasion by genetic and pharmacological targeting of MDA-9/syntenin. Proc Natl Acad Sci USA 114(2): 370-375, 2017.
31 Rollin J, Iochmann S, Blechet C, Hube F, Regina S, Guyetant S, Lemarie E, Reverdiau $\mathrm{P}$ and Gruel Y: Expression and methylation status of tissue factor pathway inhibitor- 2 gene in non-small-cell lung cancer. Br J Cancer 92(4): 775-783, 2005.

32 Wang S, Xiao X, Zhou X, Huang T, Du C, Yu N, Mo Y, Lin L, Zhang J, Ma N, Murata M, Huang $\mathrm{G}$ and Zhang Z: TFPI2 is a putative tumor suppressor gene frequently inactivated by promoter hypermethylation in nasopharyngeal carcinoma. BMC Cancer 10: 617, 2010.

33 Wong CM, Ng YL, Lee JM, Wong CC, Cheung OF, Chan CY, Tung EK, Ching YP and Ng IO: Tissue factor pathway inhibitor2 as a frequently silenced tumor suppressor gene in hepatocellular carcinoma. Hepatology 45(5): 1129-1138, 2007.

34 Rao CN, Lakka SS, Kin Y, Konduri SD, Fuller GN, Mohanam $\mathrm{S}$ and Rao JS: Expression of tissue factor pathway inhibitor 2 inversely correlates during the progression of human gliomas. Clin Cancer Res 7(3): 570-576, 2001.

35 Konduri SD, Rao CN, Chandrasekar N, Tasiou A, Mohanam S, Kin Y, Lakka SS, Dinh D, Olivero WC, Gujrati M, Foster DC, Kisiel W and Rao JS: A novel function of tissue factor pathway inhibitor-2 (TFPI2) in human glioma invasion. Oncogene 20(47): 6938-6945, 2001.
Received November 30, 2018

Revised December 13, 2018

Accepted December 14, 2018 